\title{
Конфликтологическая компетентность
}

\section{подростков: теоретическая модель}

\author{
С. С. Антипина ${ }^{1}$ \\ 1 Российский государственный педагогический университет им. А. И. Герцена, \\ 191186, Россия, Санкт-Петербург, наб. р. Мойки, 48
}

\section{Сведения об авторе:}

Антипина Светлана Степановна e-mail: sveta-anti@mail.ru ORCID: 0000-0002-6807-8141

(C) Автор (2019).

Опубликовано Российским государственным педагогическим университетом им. А. И. Герцена.

Аннотация. Проблема конфликтного поведения подростков становится в настоящее время все более актуальной. С этой позиции важным ресурсом развития межличностного общения выступает конфликтологическая компетентность. Понятие «конфликтологическая компетентность» в психологии стало изучаться сравнительно недавно. В статье представлена теоретическая модель конфликтологической компетентности подростков. Проанализировано понятие «компетентность», так как именно оно легло в основу конфликтологической компетентности. Теоретическую основу составили подходы Равена Дж., Кашапова М. М., Харитонова Е. В., Марковой А. К., Петровской Л. А., Хуторского А.В. На основе этого анализа была выделена структура компетентности, ее показатели и признаки. Далее рассмотрены различные подходы к определению понятия конфликтологической компетентности. В основу легли работы Хасана Б. И., Чекмаревой Г. В., Цой Л. Н., Зазыкина В. Г. и др. В работах авторов основной акцент делается на наличие знаний в области взаимодействия (знаниевый/когнитивный компонент) и стратегию поведения в конфликте (поведенческий компонент). Предложена модель конфликтологической компетентности, которая включает в себя следующие компоненты:

- интеллектуально-познавательный компонент включает в себя не только знания, связанные с конфликтом, стратегии поведения в нем, а также свойства личности, которые помогают наилучшим способом воспользоваться, имеющимися знаниями, умениями и навыками;

- мотивационно-ценностный компонент - направленность на адекватное поведение в конфликте, ценностные ориентиры (принятие, понимание других людей и их поведения, мотивация строить отношения на основе диалога, мотивация на достижение доверия в межличностном взаимодействии, мотивация на разрешение конфликтов);

- эмоционально-волевой компонент включает в себя адекватную самооценку, эмоциональную устойчивость в трудных ситуациях межличностного взаимодействия, а также психологические качества личности, детерминирующие поведение;

- действенно-практический компонент включает коммуникативные умения и навыки, связанные со способностью устанавливать доверительные отношения, понимать точку зрения других участников взаимодействия; способность организовывать межличностные отношения на принципах гуманизма; конструктивные умения и навыки, связанные со способностью подростков ставить задачи по конструктивному разрешению конфликта, прогнозировать развитие конфликтных ситуаций; способность и готовность минимизировать деструктивные формы конфликта.

Ключевые слова: подростки, конфликт, компетентность, конфликтологическая компетентность. 


\title{
Conflictological competence of adolescents: A theoretical model
}

\author{
S. S. Antipina ${ }^{1}$ \\ ${ }^{1}$ Herzen State Pedagogical University of Russia, \\ 48 Moika River Emb., Saint Petersburg 191186, Russia
}

\begin{abstract}
Author:
Antipina Svetlana $S$.

e-mail: sveta-anti@mail.ru

ORCID: 0000-0002-6807-8141

Copyright:

(C) The Author (2019).

Published by Herzen State

Pedagogical University of Russia.
\end{abstract}

\begin{abstract}
The problem of conflict on the part of adolescents is now becoming increasingly relevant. From this position, conflictological competence is an important resource for the development of interpersonal communication. The concept of "conflictological competence" in psychology has been studied only relatively recently. The article presents a theoretical model for assessing adolescents' conflictological competence. The concept of "competence" is analysed as a basis for establishing the notion of conflictological competence. The theoretical basis stems from the approaches of J. Raven, M. M. Kashapov, E. V. Kharitonov, A. K. Markova, L. A. Petrovskaya, and A. V. Khutorsky. Based on this analysis, the structure of
\end{abstract} competence, its indicators and distinguishing characteristics, was highlighted. Then various approaches to the definition of the concept of conflictological competence were considered based on the work of B. I. Hasan, G. V. Chekmareva, L. N. Tsoi, V. G. Zazykina. The authors focus on the presence of knowledge in the field of interaction (the knowledge/cognitive component) and behaviour strategies in conflicts (the behavioral component). A conflictological competency model including the following components is proposed:

- the intellectual-cognitive component includes knowledge related to the conflict, behavioural strategies within it, as well as personality traits that make the best use of available knowledge, skills and abilities; - the motivational-value component focuses on appropriate behaviour in a conflict, value orientations (the acceptance of understanding other people and their behaviour along with the motivation to build trust in interpersonal interaction, to resolve conflicts, and to build relationships based on dialogue);

- the emotional-volitional component includes adequate self-esteem, emotional stability in difficult interpersonal situations, as well as the psychological qualities of a person that determine behavior;

- an effective and practical component includes communicative skills related to the ability to establish trusting relationships, understand the point of view of other participants in the interaction, the ability to organize interpersonal relationships on the principles of humanism, constructive skills related to the ability of adolescents to set tasks for constructive conflict resolution and to predict the development of conflict situations, and the ability and willingness to minimize destructive forms of conflict.

Keywords: adolescents, competence, conflictological competence, conflict.

\section{Введение}

В современном обществе проблема конфликтного поведения подростков становится всё более актуальной. Подростки активно взаимодействуют с различными социальными группами. Но в силу своего возраста они не обладают достаточными знаниями и опытом, чтобы организовать эффективное взаимодействие. По данным
Немковой А. Б., 28 \% учащихся старших классов имеют низкий уровень знаний о конфликте и возможных вариантах его разрешения, у 46,7 \% знания хаотичны и только у 18,3 \% подростков эти знания носят системный характер (Немкова 2007). Именно подростковый возраст является наиболее благоприятным для развития навыков взаимодействия с окружающими. 
Отказ от решения этой задачи в данный период может привести к серьезным личностным проблемам в дальнейшем. Поэтому развитие конфликтологической компетентности в этом возрасте является наиболее важным. Несмотря на огромное количество работ, посвященных подростковым конфликтам, проблема конфликтологической компетентности подростков в настоящее время разрабатывается фрагментарно, без углубленных обобщающих исследований.

В связи с этим актуальной представляется разработка вопроса о содержании структуры конфликтологической компетентности подростков. Одной из задач нашего исследования стал анализ научнометодической литературы с целью изучения понятия и структуры конфликтологической компетентности, результаты которого помогут сформулировать более точно структуру конфликтологической компетентности подростков.

\section{Результаты}

Прежде чем анализировать понятие «конфликтологическая компетентность», необходимо изучить понятие «компетентность», которое легло в его основу. В психологической энциклопедии данное понятие рассматривается «как степень овладения нужными умениями и навыками», которые помогают справиться с определенной ситуацией, выбрать нужное поведение (Корсини, Ауэрбах 2006). В новейшем психологическом словаре компетентность описывается, как «психосоциальное качество, означающее силу и уверенность... которое дает человеку осознание своей способности эффективно взаимодействовать с окружением» (Шапарь 2005, 203). В данном определении компетентность рассматривается как психосоциальное качество, образуемое под влиянием социума.

Исследуя в дальнейшем понятие «компетентность», мы обнаружили, что оно состоит из ряда компонентов, при этом различные авторы выделяют в качестве ведущих разные компоненты. Например, Каша- пов М. М., анализируя понятие «компетентность», акцентирует внимание на когнитивном компоненте в структуре компетентности (Кашапов 2006). В работе Равена Дж. модель компетентности связана с признанием определяющего и системообразующего значения ценностно-мотивационной сферы личности. Он одним из первых описывает феномен компетентности, который, по его мнению, включает большое «число компонентов... некоторые компоненты относятся скорее к когнитивной сфере, а другие - к эмоциональной... эти компоненты могут заменять друг друга в качестве составляющих эффективного поведения» (Равен 2002, 96). Для автора все виды компетентности являются «мотивированными способностями», которые можно обнаружить в ситуации, наиболее значимой для личности. При этом ценностный аспект является определяющим. Таким образом, компетентность выступает интегральной характеристикой личности и является приобретаемым качеством. В подтверждении вышесказанному: Вершловский С. Г. и Кулюткин Ю. Н. рассматривают компетентность как личностную характеристику; Сластенин В. А. как совокупность коммуникабельных, конструктивных, организаторских умений личности; Панарин Л. И. - как личное качество субъекта, его специализированной деятельности в системе социального и технического разделения; Чошанов М. А. как совокупность трех признаков, один из которых критичность мышления, то есть способность выбирать среди множества решений наиболее оптимальное (Харитонова 2007). Из представленных определений видно, что в структуру компетентности ученые включают некоторые характеристики мышления, это могут быть творческие характеристики, позволяющие переносить имеющиеся знания и умения в новые области их применения, самостоятельность в принятии решений, способность к разрешению проблем и прочие.

Проведенный анализ различных подходов к определению компетентности поз- 
волил сделать несколько выводов. Во-первых, исследователи отмечают деятельностную, актуальную сущность компетентности, подчеркивая, что по мимо знаниевой характеристики, то есть характеристики «что», акцентируется способ и характер действия «как». Во-вторых, большинство исследователей отмечают личностную, в частности мотивационную характеристику компетентности. В-третьих, исследователи фиксируют сложный характер этого явления как в его определении, так и в оценке.

Итак, опираясь на труды Хуторского А.В. и других ученых, под компетентностью будем понимать комплекс взаимосвязанных личностных качеств (знаний, умений, навыков, характеристик мышления, обеспечивающих способность принимать эффективные решения, действовать рационально и т. д.), задаваемых по отношению к определенному процессу, и необходимых для продуктивных действий (Хуторской 2003). В нашем случае задаваемым процессом будет конфликтная ситуация.

Обратимся теперь к самому понятию «конфликтологическая компетентность». В научной литературе существуют различные подходы к определению данного понятия. По мнению Хасана Б. И., Чекмаревой Г. В., Петровской Л. А, Клементьевой А. Я., конфликтологическая компетентность - это способность осуществлять деятельность, некий набор умений и навыков, которые помогают выстраивать общение, упреждать, минимизировать конфликты, переводить их в социально-позитивное русло. Таким образом, конфликтологическая компетентность представляет собой уровень знаний о возможных стратегиях поведения конфликтующих сторон и умение в конкретной ситуации конфликта выстраивать эффективное взаимодействие. Данный подход дает возможность рассмотреть конфликтологическую компетентность на двух уровнях. Первый включает способности к распознаванию и осознанию конфликта, владение способами урегулирования конфликтных ситуаций. Второй - умение воссоздать в определенной ситуации взаимодействия конфликты, необходимые для достижения поставленных целей. В этих определениях основной акцент сделан на наличие знаний в области взаимодействия (знаниевый /когнитивный компонент).

Масюкевич Н. В., Немкова А. Б., Бегмаганбетова Г. Г. определяют конфликтологическую компетентность как способность и готовность к осуществлению деятельности по профилактике конфликта, осведомленность о диапазоне возможных стратегий поведения в конфликтной ситуации и способности использовать ту или иную стратегию в зависимости от ситуации. Вновь упор сделан на теоретические знания, но в этот раз они относятся к стратегии поведения в конфликте, возможности выбрать наиболее подходящую. Можно сделать вывод, что данные знания не узко ограничены, а изменяются в зависимости от ситуации (поведенческий компонент).

Ряд ученых под конфликтологической компетентностью понимают характеристики личности, которые позволяют эффективно реализовать себя в ситуации межличностного конфликта. Ивченко Д. В. под конфликтологической компетентностью понимает гибкость ума, саногенное мышление, уровень тревожности, уровень самооценки, уровень уверенности в себе, уровень субъективного самоконтроля (Ивченко 2000). По мнению Цой Л.Н., конфликтологическая компетентность представляет собой целеустремленность, рефлексивность, коммуникативность, социальность, готовность к развитию (Цой 2001). Немкова А. Б. выделяет креативность, толерантность, рефлексию, отсутствие конфликтофобии (Немкова 2007). Яковлева И. П. - эмоциональную устойчивость, эмпатию, альтруизм (Яковлева 2015). Бояр Д. С. - коммуникативные и ор- 
ганизаторские склонности, эмпатию, толерантность, степень конфликтности, бескомпромиссность, напористость, вспыльчивость, мнительность, подозрительность. Крылова Т. А. - конфликтоустойчивость, ассертивность, стрессоустойчивость (Крылова 2016). Это позволило предположить наличие в структуре конфликтологической компетентности еще неких компонентов, включающих особенности личности (это может быть эмоционально-волевой, коммуникативный или другой компонент).

Из представленного выше мы видим, что сама категория «конфликтологическая компетентность» до сих пор не имеет однозначного определения и понимается как синоним высокого уровня профессионализма, как личностное качество человека, получившего образование (определенную ступень), выражающееся в готовности (способности) на его основе к успешной деятельности с учетом ее социальной значимости и социальных рисков. Однако при этом во всех вариантах описания в качестве обязательного компонента выступает умение конструктивно взаимодействовать с людьми, способность смягчать разногласия и разрешать конфликты.

Учитывая имеющиеся трактовки понятия конфликтологической компетентности, попытаемся выстроить ее структуру на основе обобщения имеющейся информации.

На сегодняшний день у исследователей не существует единого подхода относительно структуры конфликтологической компетентности. Ряд авторов (Бережная Г. С., Ефимова Е. Е., Ивченко Д. В., Маркарова К. Э. и др.) считают, что конфликтологическая компетентность имеет трехкомпонентную структуру, предполагающую сочетание содержательной (система научных знаний о конфликте), деятельностной (спектр необходимых умений и навыков поведения в конфликтных ситуациях, различные стратегии взаимодействия, технологии управления конфликтом) и личностной сфер (развитая рефлек- сивная сфера, эмпатия, гибкость поведения, эмоциональная устойчивость, ценностные ориентации, направленность на партнеров по взаимодействию).

Леоновым Н. И. была предложена структурно-динамическая модель конфликтологической компетентности. В структурные составляющие автор выделил социально-психологические, операциональные и поведенческие характеристики личности. В динамические - характеристики, определяемые спецификой деятельности и ситуацией непосредственного взаимодействия (Леонов 2011).

Анцупов А. Я. и Шипилов А. И. к структурно-содержательным компонентам конфликтологической компетентности относят понимание специфики противоречий между людьми, навыки бесконфликтного общения, конструктивное отношение к конфликтам, способность объяснять и оценивать возникающие противоречия, управлять конфликтными явлениями и разрабатывать конструктивные сценарии регулирования проблемных ситуаций. Особую роль в их понимании играют умение предвидеть возможные последствия конфликтов, а также навыки устранения этих негативных последствий (Анцупов, Шипилов 2004).

Петровская Л. А. предлагает рассматривать структуру конфликтологической компетентности через основные характеристики конфликтного общения. С этой точки зрения основными составляющими конфликтологической компетентности выступают: компетентность участника в собственном Я («Я-компетентность»), то есть его реальная оценка собственного психологического потенциала, а также потенциала другого участника (участников), и ситуационная компетентность. Автор выделяет следующие составляющие конфликтологической компетентности: формирование конструктивного отношения к конфликтам в организации, умение оценивать и объяснять возникающие проблемные ситуации, умение конструктивно регулировать противоречия и конфликты, наличие навыков устранения негативных 
последствий конфликтов (Петровская 1997).

Зазыкиным В. Г. проблема конфликтологической компетентности была разработана на концептуальном уровне. Данная концепция предполагает выделение в структуре конфликтологической компетентности следующих компонентов: гностический (знания о причинах возникновения конфликтов, особенностях поведения и психического состояния оппонентов, применяемых приемах конфликтного единоборства); регулятивный (умение воздействовать на оппонентов, умение разрешать конфликт на справедливой и конструктивной основе, умение организовывать работу в постконфликтной ситуации); проектировочный (умение на основе имеющихся знаний предвосхищать поведение и деятельность оппонентов в конфликте); рефлексивно-статусный (рефлексия собственного поведения, общения, деятельности и отношений); нормативный (знание этических норм поведения и отношений, следование им). Такой системный подход позволяет определить комплексный характер восприятия и анализа конфликтов, обладающих внутренней взаимосвязанной структурой, функциями и коммуникациями со средой (Зазыкин 1998).

Ряд исследователей при выделении структурных компонентов опирались на степень сформированности функций конфликтологической компетентности (Немкова А.Б., Яковлева И. П., Ярослав Л. О.). Их структуру составили: мотивационный, включающий побуждения, связанные с конфликтной ситуацией, объясняющие внутренние силы, которые благоприятствуют адекватному поведению в конфликте; когнитивный, реализующийся через систему знаний о структуре и динамике конфликта, стратегиях поведения, барьерах в общении, профилактике конфликта, ведении переговоров; поведенческий, включающий умение эффективно организовывать взаимодействие (бесконфликтное); ценностно-смысловой, представляющий отношение к конфликту как к норме взаимодействия между людьми; как способу отстаивания собственной точки зрения; разрешение конфликта, в котором обе стороны достигают свои цели, при взаимной направленности на партнера; эмоционально-волевой саморегуляции, проявляющейся в адекватной самооценке, способности управлять эмоциями в предконфликтных ситуациях и непосредственно в процессе конфликтного взаимодействия, особенно гневом, способности и готовности к эмпатии, рефлексии, самокритичности, умении достичь в конфликте целей самоактуализации и саморазвития, инициативности.

Учитывая проведенный анализ понятия и структуры конфликтологической компетентности, мы сформулировали структуру, которая, по нашему мнению, наиболее полно описывает составные компоненты. Структура конфликтологической компетентности представлена в таблице.

\section{Выводы}

Таким образом, проведенный теоретический анализ психолого-педагогической литературы свидетельствует о том, что в настоящее время отсутствует общепринятый подход к рассмотрению структурных составляющих конфликтологической компетентности и нет единых критериев для выделения ее компонентов. В частности, проблематичными остаются показатели конфликтологической компетентности личности, психологических и личностных особенностей, с которыми связано ее развитие. Проведенный сравнительный анализ различных подходов позволил нам сделать вывод о необходимости четкой интеграции отдельных личностных качеств в компоненты, составляющие структуру конфликтной компетентности свойственной именно подростковому возрасту. 


\section{Таблица. Структура конфликтологической компетентности}

\begin{tabular}{|c|c|}
\hline $\begin{array}{c}\text { Компо- } \\
\text { нент }\end{array}$ & Характеристика \\
\hline 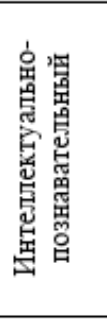 & $\begin{array}{l}\text { Включает не только владение знаниями, связанными с конфликтом, поннмание } \\
\text { сущности конфликта, причин его возннкновения, развития, разрешення н преодо- } \\
\text { лення последствий, но и свойства личностн, которые помогают использовать, нме- } \\
\text { ющиеся знания н умения для достижения положительного результата. Это может } \\
\text { быть гибкость и оперативность в аналнзе ситуацнй межличностных отношений, } \\
\text { интеллектуальная инициатива (как свойство личности), готовность выйти за пре- } \\
\text { делы заданного, самоорганизация, предполагающая способность анализировать } \\
\text { ситуацин конфликтологического характера, креативность. Подростки уже обла- } \\
\text { дают набором неких знаний о конфликте, но не всегда үмеют их применять. }\end{array}$ \\
\hline 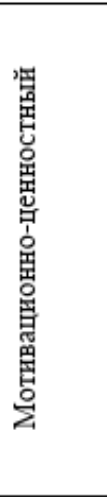 & $\begin{array}{l}\text { Включает систему ценностных орнентаций, связанных с нравственными н духов- } \\
\text { ными ндеалами, направленность на построение отношений на основе диалога, мо- } \\
\text { тнвация на конструктивное разрешение конфликтов. Ценностное отношение к } \\
\text { межличностному взаимодействню. Приняте, понимание други людей и их пове- } \\
\text { дения. Это не только направленность на адекватное поведенне в конфликте, но и } \\
\text { более глубокне ценностные орнентиры. В нашей структуре мы объединили два } \\
\text { компонента мотивационный и ценностно-смысловой. Данный компонент вызы- } \\
\text { вает нанбольшее непонимание в подростковом возрасте. Мотнвация у подростков } \\
\text { строится на признании себя взрослым и оценки себя через эту призму. Формиру- } \\
\text { ется «внутренний план», однако этот «внутренний план»еще не организован в це- } \\
\text { лостную систему, недостаточно обобщен и устойчив. Кроме того, характерным } \\
\text { для данного возраста является несоответствие целей возможностям, что свиде- } \\
\text { тельствует о завышенном уровне притязаний и является прнчнной частых неудач } \\
\text { в осуществлении задуманного. }\end{array}$ \\
\hline 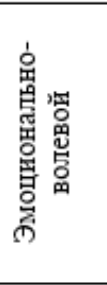 & $\begin{array}{l}\text { Включает способность личности к осознанному управлению своим эмоционально- } \\
\text { волевым состоянием в конфликтных и предконфликтных ситуациях, адекватную } \\
\text { самооценку, позитнвный эмоциональный фон настроения, отсутствие длительных } \\
\text { деструктивных состояний (тревоги, паникн, отчаяния, страха, агрессии), налнчне } \\
\text { эмпатин, решительность, настойчивость, целеустремленность, ассертивность, то } \\
\text { есть психологические качества лнчности, которые определяют поведение инди- } \\
\text { вида. В силу своих возрастных особенностей подросткам сложно справиться со } \\
\text { свонми эмоциями, что может способствовать развитню конфлнктных ситуаций. }\end{array}$ \\
\hline 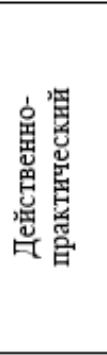 & $\begin{array}{l}\text { Включает умение общаться, выстраивать взаимоотношения на основе конструк- } \\
\text { тнвного взаимодействия, умение проектировать свое взаимодействие как бескон- } \\
\text { фликтное; установление и соблюдение правил ведения переговоров; владение ши- } \\
\text { рокнм спектром стратегий поведения в конфликте и адекватное их использование; } \\
\text { профнлактика и разрешение конфликтов, предотвращение их последствий. В слу- } \\
\text { чае возникновения конфликтных снтуаций подросткн могут использовать различ- } \\
\text { ные способы поведения: от избегания до активного включения в конфликт. Дан- } \\
\text { ный компонент рассматривает более глубоко и полно поведенческую составляю- } \\
\text { щую конфликтологической компетентности. Уделяется отдельное вниманне ком- } \\
\text { муникативной сфере, важной именно для подросткового возраста. }\end{array}$ \\
\hline
\end{tabular}

\section{Литература}

Анцупов, А. Я., Шипилов, А. И. (2004) Конфликтология. М.: Юнити-Дана, 207 с. Бекмаганбетова, Г. Г. (2009) К вопросу о формировании конфликтной компетентности в младшем школьном возрасте. Начальная школа плюс. До и После, № 4, с. 83-85.

Зазыкин, В.Г. (1998) Конфликтологическая компетентность как фактор развития профессионализма государственных служащих. В кн.: Материалы научнопрактической конференции «Российское государство и государственная служба на современном этапе». М.: РАГС, с. 264-266.

Ивченко, Д.В. (2000) Формирование конфликтологической компетентности специалиста таможенной службы: автореферат дис. ... канд. пед. наук. Калининград, 20 с.

Кашапов, М. М. (2006) Основы конфликтологии. Ярославль: ЯрГУ, 116 с. Корсини, Р., Ауэрбах, А. (ред.). (2006) Психологическая энциклопедия. СПб.: Питер, 1096 с. 
Крылова, Т.А. (2016) Конфликтологическая компетентность курсантов как фактор противостояния стрессам. Universum: Психология и образование: электронный научный журнал, № 11 (29). [Электронный ресурс]. URL: http://7universum.com/ $\mathrm{ru} / \mathrm{psy} /$ archive/item/3853 (дата обращения 01.09.2019).

Леонов, Н.И. (2011) Конфликтологическая компетентность педагога. В кн.: Андрущенко, Т. Ю., Крицкий, А. Г., Меркулова, О.П. (ред.), Психология образования в ХХІ веке: теория и практика. Волгоград: Перемена, с. 425-428.

Немкова, А.Б. (2007) К вопросу о становлении конфликтологической компетенции старшеклассников в условиях внеклассной деятельности. Журнал научных публикаций аспирантов и докторантов, № 10, с. 151-154.

Петровская, Л. А. (1997) К вопросу о природе конфликтной компетентности. Вестник Московского университета, сер. 14, Психология, № 4, с. 41-45.

Равен, Дж. (2002) Компетентность в современном обществе: выявление, развитие и реализация. М.: Когито-Центр, 96 с.

Харитонова, Е. В. (2007) Об определении понятий «компетентность» и «компетенция». Успехи современного естествознания, № 3, с. 67-68.

Хасан, Б.И. (1996) Психотехника конфликта и конфликтная компетентность. Красноярск: Красноярский госуниверситет, 49 с.

Хуторской, А.В. (2003) Ключевые компетенции как компонент личностноориентированной парадигмы. Народное образование, № 2, с. 58-64.

Цой, Л. Н. (2001) Практическая конфликтология. Книга первая. М.: Глобус, 233 с.

Чекмарева, Г. (2010) Развиваем конфликтологическую компетентность. Кадровое дело, № 2, c. 86-91.

Шапарь, В. Б. (ред.) (2005) Новейший психологический словарь. Ростов н/Д.: Феникс, 203 с. Яковлева, И. П., Романов, Д. А., Романова, М. А. (2015) Диагностика конфликтологической компетентности студентов в структуре психолого-педагогического мониторинга. Научный журнал КубГАУ, № 108 (04), с. 740-760.

\section{References}

Antsupov, A. Ya., Shipilov, A. I. (2004) Konfliktologiya [Conflict management]. M.: Yuniti-Dana Publ., 207 p. (In Russian)

Bekmaganbetova, G. G. (2009) K voprosu o formirovanii konfliktnoi kompetentnosti v mladshem shkol'nom vozraste [On the issue of the formation of conflict competence in primary school age]. Nachal'naya shkola plyus Do i Posle [Elementary school plus. Before and After], no. 4, pp. 83-85. (In Russian)

Chekmareva, G. (2010) Razvivaem konfliktologicheskuyu kompetentnost' [Develop conflict competency]. Kadrovoe delo [HR case], no. 2, pp. 86-91. (In Russian)

Ivchenko, D.V. (2000) Formirovanie konfliktologicheskoi kompetentnosti spetsialista tamozhennoi sluzhby [Formation of conflictological competence of a customs specialist]: PhD thesis. Kaliningrad, 20 p. (In Russian)

Kashapov, M. M. (2006) Osnovy konfliktologii [The basics of conflict management]. Yaroslavl': YarGU Publ., 116 p. (In Russian)

Kharitonova, E. V. (2007) Ob opredelenii ponyatii "kompetentnost'" i "kompetentsiya" [On the definition of the concepts of "competence" and "competence"]. Uspekhi sovremennogo estestvoznaniya [The successes of modern science], no. 3, pp. 67-68. (In Russian)

Khasan, B. I. (1996) Psikhotekhnika konflikta i konfliktnaya kompetentnost' [Psychotechnics of conflict and conflict competence]. Krasnoyarsk: KGU Publ., 49 p. (In Russian) 
Khutorskoi, A. V. (2003) Klyuchevye kompetentsii kak komponent lichnostno-orientirovannoi paradigm [Key competencies as a component of a personality-oriented paradigm]. Narodnoe obrazovanie [Public education], no. 2, pp. 58-64. (In Russian)

Korsini, R., Auerbakh, A. (Ed.) (2006) Psikhologicheskaya entsiklopediya [Psychological Encyclopedia]. St. Petersburg: Piter, 1096 p. (In Russian)

Krylova, T.A. (2016) Konfliktologicheskaya kompetentnost' kursantov kak faktor protivostoyaniya stressam [Conflict competence of cadets as a factor in resisting stress]. Universum: Psikhologiya i obrazovanie: elektron. nauchn. zhurn. [Psychology and education], no. 11 (29). [Online]. Available at: URL: http://7universum.com/ru/psy/archive/item/3853 (accessed 01.09.2019). (In Russian)

Leonov, N. I. (2011) Konfliktologicheskaya kompetentnost' pedagoga [Conflict competence of the teacher]. In: Andrushchenko T. Yu., Kritskii A. G., Merkulova O. P. (eds.) Psikhologiya obrazovaniya $v$ XXI veke: teoriya i praktika [Psychology of education in the XXI century: theory and practice], Volgograd: Peremena, pp. 425-428. (In Russian)

Nemkova, A. B. (2007) K voprosu o stanovlenii konfliktologicheskoi kompetentsii starsheklassnikov v usloviyakh vneklassnoi deyatel'nosti [Conflict competence of cadets as a factor in resisting stress]. Zhurnal nauchnykh publikatsii aspirantov i doktorantov [Journal of scientific publications of graduate and doctoral students], no. 10, pp. 151-154. (In Russian)

Petrovskaya, L. A. K voprosu o prirode konfliktnoi kompetentnosti [On the nature of conflicting competence]. Vestnik Moskovskogo universiteta, ser. 14, Psikhologiya [Bulletin of Moscow University, ser. 14 Psychology], no. 4, pp. 41-45. (In Russian)

Raven, Dzh. (2002) Kompetentnost' $v$ sovremennom obshchestve: vyyavlenie, razvitie $i$ realizatsiya [Competence in modern society: identification, development and implementation]. M.: Kogito-Tsentr Publ., 96 p. (In Russian)

Tsoi, L. N. (2001) Prakticheskaya konfliktologiya [Practical conflictology]. Book 1. M.: Globus Publ., 233 p. (In Russian)

Zazykin, V.G. (1998) Konfliktologicheskaya kompetentnost' kak faktor razvitiya professionalizma gosudarstvennykh sluzhashchikh [Conflict competence as a factor in the development of professionalism of civil servants]. In: Materialy nauchno-prakticheskoi konferentsii «Rossiiskoe gosudarstvo i gosudarstvennaya sluzhba na sovremennom etape» [The Russian state and civil service at the present stage]. M.: RAGS Publ., pp. 264-266. (In Russian) 